\title{
Macroeconomic convergence in the West African monetary zone: Evidence from rank tests
}

\author{
Emmanuel N. Gyamfi ${ }^{1 *} \bullet$ Anokye M. Adam ${ }^{2} \cdot$ Emily F. Appiah $^{3}$ \\ ${ }^{1}$ School of Business, Ghana Institute of Management and Public Administration, Ghana \\ ${ }^{2}$ School of Business, University of Cape Coast, Ghana \\ ${ }^{3}$ Central University, Ghana
}

\begin{abstract}
This article examined convergence of inflation and exchange rates in six (6) West African countries that make up the West African Monetary Zone (WAMZ). A non-parametric rank and score test was employed in the analysis. The results show that inflation and nominal exchange rates of Gambia, Ghana, Guinea, Liberia, Nigeria and Sierra Leone are converging. The findings have practical implications.
\end{abstract}

Keywords: macroeconomic convergence; WAMZ; rank and score test

JEL Classification Codes: C10, C13, C32

\section{Introduction}

The introduction of a common currency for six West African countries constituting the West African Monetary Zone (WAMZ) has been long over-due. Five countries consisting of Gambia, Ghana, Guinea, Nigeria and Sierra Leone in the year 2000 agreed to have a common currency known as the ECO. Liberia joined after the year 2000.

From the year 2000 till now, the ECO is still not in circulation of these countries after several postponement of implementation dates. On October 24, 2017, heads of governments of these six countries agreed to make sure the ECO is in circulation by the year 2020. However, if these countries can have a common currency, then there should be economic convergence, Adam et al. (2010). This is to say that some macroeconomic indicators should be converging in order to bring about smooth policy implementation. The reason for economic convergence is that policy coordination, stability of the monetary union would not be threatened, Jayaraman et al. (2007).

Studies on a common currency for the WAMZ have been reported in the literature. For example, Harvey and Cushing (2015) reported from their study that countries in the zone will respond differently with an introduction of a common currency policy because of the

\footnotetext{
*Corresponding author. E-mail: engyamfi@gimpa.edu.gh.

Citation: Gyamfi, E. M., Adam, A. M., and Appiah, E. F. (2019) Macroeconomic convergence in the West African monetary zone: Evidence from rank tests, Economics and Business Letters, 8(4), 191-198.
}

DOI: 10.17811/ebl.8.4.2019.191-198 
asymmetrical response these countries have to common supply, demand and monetary shocks. Harvey and Cushing (2015) therefore concluded that a common currency should be implemented when the economies of these countries converge further. Also, studies by Saka et al. (2015), Alagidede and Tweneboah (2015) also posit that further convergence of these economies are necessary for a successful common currency regime.

However, it must be stated that most of the previous studies analyzed economic convergence using linear methods. The use of linear methods in economic convergence analysis have been argued by researchers such as Dyckman and Morse (1986) and Lee et al. (2001) to produce misleading results. These researchers posit that the data generating process of a financial data is not linear and hence analyzing financial data with linear methods might lead to misleading conclusions.

It is against these backgrounds that this study was carried out. This study therefore aims at investigating whether two macroeconomic indicators; inflation (which is proxied by the consumer price index (CPI)) and nominal exchange rates of these countries against the US dollar are converging. If these macroeconomic indicators are converging, then we can be assured that the pledge of implementation date by the year 2020 as given by the governments of these six countries is feasible if these governments will give in the needed attention going forward.

Because of the misleading conclusions that linear methods can have on financial data analysis, we employ a non-linear Breitung (2001) rank and score test of cointegration. The Breitung (2001) test is a non-parametric test which is appropriate in testing for convergence because it does not require the functional form to be exact for estimation as parametric tests would require.

The rest of the article is organized as follows: Section 2 discusses the data used in the study, section 3 describes the rank and score test of Breitung (2001). Section 4 presents and discusses the results obtained while section 5 concludes the study.

\section{Data}

The natural logarithm of monthly data on inflation which was proxied by the consumer price index (CPI) and nominal exchange rates with the US dollar for the six countries were taken. The data period for CPI was from 2006M01 to 2017M05 while the data period for nominal exchange rate was from 1985M01 to 2017M05. The data was obtained from the International Financial Statistics (IFS) of the International Monetary Fund (IMF).

\section{Methodology}

\subsection{Rank and Score Test of Breitung (2001)}

The rank test investigates the null of no cointegration between two or more variables. We test the null of no cointegration between the nominal exchange rate (denoted $e_{t}$ ) of Nigeria and the nominal exchange rate of each of the remaining five countries (denoted $r_{t}$ ) against an alternative of cointegration of either linear or nonlinear form. If the null hypothesis of the rank test is rejected, we use the score test to investigate if the cointegration between the nominal exchange rates is linear or nonlinear. Nigeria was taken as the base country because of the large population numbers and the highest GDP per capita. According to the World Bank, Nigeria's GDP per capita in 2016 was about $\$ 2178$ which was the highest amongst the countries under study. Rank test cointegration between Nigeria's CPI and each of the CPIs of the five countries were also investigated.

\subsubsection{Rank test}

Following Breitung (2001), we let $y_{t}$ be a series and $\mathrm{R}\left(y_{t}\right)$ be the rank of $y_{t}$ among $\left(y_{1} y_{2} y_{3}\right.$ $\left., \ldots, y_{T}\right)$ where $y_{t}=\left\{e_{t}, r_{t}\right\}$ and $\mathrm{T}$ is the sample size. 
Based on the differences between the sequences of ranks, Breitung (2001) defined two rank test statistics as:

$$
\begin{gathered}
B_{1}=\frac{\sup _{1<t<T}\left|d_{t}\right|}{T} \\
B_{2}=\sum_{t=1}^{T} \frac{d_{t}^{2}}{T^{3}}
\end{gathered}
$$

Where $d_{t}=R\left(e_{t}\right)-R\left(r_{t}\right)$ assuming that $R\left(e_{t}\right)$ and $R\left(r_{t}\right)$ are both monotonically increasing or decreasing. Since $e_{t}$ and $r_{t}$ are assumed to be mutually serially uncorrelated random walks, Breitung (2001) relaxed this assumption and made corrections to the two statistics as:

$$
\begin{gathered}
B_{1}^{*}=\frac{\sup _{1<t<T}\left|d_{t}\right|}{T \hat{\sigma}_{\Delta d}} \\
B_{2}^{*}=\sum_{t=1}^{T} \frac{d_{t}^{2}}{T^{3} \hat{\sigma}^{2} \Delta d}
\end{gathered}
$$

Where $\hat{\sigma}_{\Delta d}^{2}=T^{-2} \sum_{t=1}^{T}\left(d_{t}-d_{t-1}\right)^{2}$ is used to adjust for the possible correlation between $e_{t}$ and $r_{t}$. To extend cointegration among more than two variables, Breitung (2001) specified a rank test statistic for multivariables as:

$$
B_{3}^{*}[k]=T^{-3} \sum_{t=1}^{T}\left(\hat{\mu}_{t}^{R}\right)^{2} / \hat{\sigma}_{\Delta \widehat{\mu}}
$$

Where $\tilde{\mu}_{t}^{R}=R\left(e_{t}\right)-\tilde{b} R\left(r_{t}\right)$ in which $\tilde{b}$ is the least squares estimates from a regression of $R\left(e_{t}\right)$ on $R\left(r_{t}\right)$ and $\tilde{\mu}_{t}^{R}$ are the estimated residuals. We use $\hat{\sigma}^{2}{ }_{\Delta d}=T^{-2} \sum_{t=2}^{T}\left(\tilde{\mu}_{t}^{R}-\tilde{\mu}_{t-1}^{R}\right)^{2}$ to adjust for possible correlation amongst the variables.

In this study, $B_{3}^{*}[k]$ was extended to test for the long-run relationship between nominal exchange rate $e_{t}$, domestic prices $p_{t}$ and foreign prices $p_{t}^{*}$. Here, $\tilde{\mu}_{t}^{R}=R\left(e_{t}\right)-\widetilde{b_{1}} R\left(p_{t}\right)$ $\tilde{b}_{2} R\left(p_{t}^{*}\right)$ where $\tilde{b}_{1}$ and $\tilde{b}_{2}$ are the least squares regression estimates from a regression of $R\left(e_{t}\right)$ on $R\left(p_{t}\right)$ and $R\left(p_{t}^{*}\right)$ and $\mathrm{k}=2$.

The null of no cointegration is rejected if the critical values are greater than the test statistic.

\subsubsection{Score test for nonlinearity}

The score test for nonlinearity is employed if the null of the rank test is rejected. Thus if $e_{t}$ and $r_{t}$ are cointegrated, we proceed to find if the cointegration relationship is linear or nonlinear. A bivariate score test statistic T.R $R^{2}$ was suggested by Breitung (2001) from the following regression:

$$
\widetilde{\mu}_{t}=c_{0}+c_{1} r_{t}+c_{2} R\left(r_{t}\right)+\vartheta_{t}
$$

Where $R^{2}$ is the coefficient of determination of the regression in equation (6), $\tilde{\mu}_{t}$ is for the residuals of the regression of $e_{t}$ on a constant and $r_{t}$. Thus $\tilde{\mu}_{t}=e_{t}-\left(\tilde{a}_{0}+\tilde{a}_{1} r_{t}\right)$ where $\tilde{a}_{0}$ and $\tilde{a}_{1}$ are the least squares estimates.

A multivariate score test statistic to test the linearity of cointegration relationship amongst $e_{t}$, $p_{t}$ and $p_{t}^{*}$ can be obtained from the following regression:

$$
\tilde{\mu}_{t}=c_{0}+c_{1} p_{t}+c_{2}\left(p_{t}^{*}\right)+c_{3} R\left(p_{t}\right)+c_{4} R\left(p_{t}^{*}\right)+\vartheta_{t}
$$

Where $\tilde{\mu}_{t}$ is for the residuals of the regression of $e_{t}$ on a constant, $p_{t}$ and $p_{t}^{*}$.

The score test statistic is asymptotically Chi-squared $\left(\chi^{2}\right)$ distributed with one degree of freedom. The null of linear cointegration (i.e. if $c_{2}=0$ (for bivariate) and $c_{3}=c_{4}=0$ (for multivariate)) is rejected in favour of a nonlinear cointegration if the test statistic T. $R^{2}$ exceeds 
the $\chi 2$ critical values of 6.63, 3.84 and 2.71 (for bivariate) and 9.21, 5.99 and 4.61 (for multivariate) at the $1 \%, 5 \%$ and $10 \%$ significance levels respectively.

\section{Results and discussion}

We use the ADF unit root test with an intercept and a trend to verify if CPI and nominal exchange rates are integrated. The results are presented in Tables 1 and 2. It is observed in Table 1 that CPI are I (1) but for Gambia and Ghana at the 5\% significance level. CPI plots are shown in Appendix A. Nominal exchange rates results shown in Table 2 are I (1) for all the countries except Ghana at the 5\% significance level.

Table 1. ADF unit root test results for CPI.

\begin{tabular}{lllll}
\hline \hline Country & $\begin{array}{l}\text { Levels } \\
\text { ADF Statistics }\end{array}$ & P-Value & $\begin{array}{l}\text { First Difference } \\
\text { ADF Statistic }\end{array}$ & P-Value \\
\hline \hline Gambia & -3.4534 & 0.0497 & -6.7120 & 0.0000 \\
Ghana & -4.2690 & 0.0052 & -8.3420 & 0.0000 \\
Guinea & -3.0860 & 0.1148 & -7.8980 & 0.0000 \\
Liberia & -2.9610 & 0.1480 & -10.0347 & 0.0000 \\
Nigeria & -1.7630 & 0.7160 & -7.8660 & 0.0000 \\
Sierra Leone & -0.6885 & 0.9710 & -1.2680 & 0.0000 \\
\hline \hline
\end{tabular}

Table 2. ADF unit root test results for Nominal Exchange Rates.

\begin{tabular}{lllll}
\hline \hline Country & $\begin{array}{l}\text { Levels } \\
\text { ADF Statistics }\end{array}$ & P-Value & $\begin{array}{l}\text { First Difference } \\
\text { ADF Statistic }\end{array}$ & P-Value \\
\hline Gambia & -2.2960 & 0.4345 & -16.2220 & 0.0000 \\
Ghana & -8.3970 & 0.0000 & -18.6150 & 0.0000 \\
Guinea & -2.1330 & 0.5248 & -18.5750 & 0.0000 \\
Liberia & -1.9800 & 0.6095 & -18.6248 & 0.0000 \\
Nigeria & -2.0924 & 0.5477 & -18.8000 & 0.0000 \\
Sierra Leone & -2.8958 & 0.1651 & -13.2520 & 0.0000 \\
\hline \hline
\end{tabular}

However, results from the Engle and Granger (1987) cointegration test show that there is no cointegration between consumer price index of Nigeria and each of the five countries under study. Also, there was no cointegration between nominal exchange rates of Nigeria and each of the five countries. Plots showing no cointegration can be provided upon request.

Because, there was no cointegration between CPI and nominal exchange rate between Nigeria and each of the five countries using the linear Engle and Granger (1987) test of cointegration, we proceed to apply the Breitung (2001) non-linear rank and score test of cointegration on our data. The Breitung (2001) non-linear rank and score test has more power than the Engle and Granger (1987) test of cointegration.

The results from Tables 3 and 4 show that the test statistics are smaller than the critical values. We therefore reject the null of no cointegration and conclude that nominal exchange rates and the consumer price index of the five countries are integrated with that of Nigeria. This means the countries are catching up with nominal exchange rates and the consumer price index of Nigeria which is seen as an economically better performing country in the WAMZ in terms of GDP per capita, Chou (2006). The findings and conclusions from Tables 3 and 4 confirms to the findings of a study on macroeconomic convergence in the WAMZ by Adam et al. (2010).

Since there is cointegration, we proceed to identify whether the cointegration is linear or nonlinear by employing the score test. 
Table 3. Rank test cointegration between nominal exchange rates.

\begin{tabular}{cccc}
\hline \hline Country & $\boldsymbol{B}_{\mathbf{1}}^{*}$ & $\boldsymbol{B}_{\mathbf{2}}^{*}$ & $\boldsymbol{B}_{\mathbf{3}}^{*}[\mathbf{1}]$ \\
\hline \hline Gambia & 0.401 & $0.0131^{* * *}$ & $0.0132^{* * *}$ \\
Ghana & 0.8901 & $0.0119^{* * *}$ & $0.0119^{* * *}$ \\
Guinea & 0.4840 & $0.0186^{* * *}$ & $0.0188^{* * *}$ \\
Liberia & $0.364^{* * *}$ & 0.0232 & $0.0236^{* * *}$ \\
Sierra Leone & 0.4118 & $0.0176^{* * *}$ & $0.0178^{* * *}$ \\
\hline \hline Critical Values & & & \\
\hline \hline $\mathbf{1 \%}$ & 0.3156 & 0.0130 & 0.0136 \\
$\mathbf{5 \%}$ & 0.3635 & 0.0188 & 0.0197 \\
$\mathbf{1 0 \%}$ & 0.3941 & 0.0232 & 0.0248 \\
\hline \hline
\end{tabular}

Notes. Rank test cointegration between nominal exchange rate of Nigeria and nominal Exchange rate of each of the five countries. ***Significance at the $10 \%$ level.

Table 4. Rank test cointegration between consumer price indices (CPI)

\begin{tabular}{cccc}
\hline \hline Country & $\boldsymbol{B}_{\mathbf{1}}^{*}$ & $\boldsymbol{B}_{\mathbf{2}}^{*}$ & $\boldsymbol{B}_{\mathbf{3}}^{*}[\mathbf{1}]$ \\
\hline \hline Gambia & 0.4322 & $0.0096^{* * *}$ & $0.0096^{* * *}$ \\
Ghana & $0.3716^{* * *}$ & $0.0125^{* * *}$ & $0.0125^{* * *}$ \\
Guinea & 0.527 & $0.018^{* * *}$ & $0.0180^{* * *}$ \\
Liberia & $0.2554^{* * *}$ & $0.009 * * *$ & $0.009^{* * *}$ \\
Sierra Leone & 0.4701 & $0.0107^{* * *}$ & $0.0106^{* * *}$ \\
\hline \hline Critical Values & & & \\
\hline \hline $\mathbf{1 \%}$ & 0.3156 & 0.0130 & 0.0130 \\
$\mathbf{5 \%}$ & 0.3635 & 0.0188 & 0.0197 \\
$\mathbf{1 0 \%}$ & 0.3941 & 0.0232 & 0.0248 \\
\hline \hline
\end{tabular}

Notes. Rank test cointegration between CPI of Nigeria and CPI of each of the five countries. $* * *$ Significance at the $10 \%$ level.

Table 5. Score test between nominal exchange rates.

\begin{tabular}{cc}
\hline \hline Country & Bivariate $\boldsymbol{T R}^{\mathbf{2}}$ \\
\hline \hline Gambia & 333.6606 \\
Ghana & 316.1457 \\
Guinea & 334.8189 \\
Liberia & 302.562 \\
Sierra Leone & 333.5553 \\
\hline \hline
\end{tabular}

Note. Score test of nonlinearity between nominal exchange rate of Nigeria and nominal exchange rates of each of the five countries.

Table 6. Score test between consumer price indices (CPI).

\begin{tabular}{cc}
\hline \hline Country & ${\text { Bivariate } \boldsymbol{T R}^{\mathbf{2}}}^{\mathbf{2}}$ \\
\hline \hline Gambia & 111.6416 \\
Ghana & 111.2048 \\
Guinea & 111.1488 \\
Liberia & 110.432 \\
Sierra Leone & 111.664 \\
\hline \hline
\end{tabular}

Note. Score test of nonlinearity between CPI of Nigeria and CPI of each of the five countries.

The results from Tables 5 and 6 show that the null of linear cointegration is rejected since $T . R^{2}$ is greater than the critical values at all significance levels. This means there is evidence of non-linear long-run co-movements within the zone. This non-linear co-movements might be 
as a result of transaction costs or the dynamic strategic behaviour in the zone. Also, the existence of trade barriers (Kilian and Taylor 2003) and interventions by governments in the foreign exchange markets (Taylor 2004) could lead to non-linear co-movements.

\section{Conclusion}

This study examined macroeconomic convergence in the WAMZ. Two macroeconomic indicators of inflation (proxied by CPI) and nominal exchange rate were examined for convergence using the Breitung (2001) non-linear rank and score test. The results show that CPI and nominal exchange rates of Gambia, Ghana, Guinea, Liberia and Sierra Leone are converging to that of Nigeria which is seen a s the largest economy within the zone with respect to GDP per capita. This means that, countries in the zone are integrated and ready for the introduction of the common currency ECO if the needed will and support would be given to its implementation by the respective governments of these countries.

\section{References}

Adam, A. M., Agyapong, D., and Gyamfi, E.N. (2010) Dynamic Macroeconomic Convergence in the West Africa Monetary Zone, International Business and Management, 1(1), 31-40.

Alagidede, P., and Tweneboah, G. (2015) Convergence of Growth Rates in the West African Monetary Zone, Journal of Economic Cooperation and Development, 36(4), 29-54

Breitung, J. (2001) Rank Tests for Nonlinear Cointegration, Journal of Business and Economic Statistics, 19, 331-340.

Chou, W. L. (2006) Convergence of Service Sector Employment in China: Panel Data Evidence, Discussion Paper in the 10th International Convention of the East Asian Economic Association, 18-19 November 2006, Beijing, China.

Dyckman, T. R., and Morse, D. (1986) Efficient Capital Markets and Accounting: A Critical Analysis, Prentice-Hall.

Engle, R. F., and Granger, C. W. J. (1987) Cointegration and error correction: Representation, estimation and testing, Econometrica, 55, 251-276.

Harvey, S., and Cushing, M. (2015) Is West African Monetary Zone a Common Currency Area?, Review of Development Finance, 5(1), 53-63.

Jayaraman, T. K., Ward B. D., and Xu, Z. L. (2007) Are the Pacific Islands Ready for a Currency Union? An Empirical Study of Degree of Economic Convergence, Journal of the Asia Pacific Economy, 12(4), 504-521.

Kilian, L., and Taylor, M. P. (2003) Why is it so difficult to beat the random walk forecast of exchange rates?, Journal of International Economics, 60, 85-107.

Lee, C.F., Chen, G.M., and Rui, O.M. (2001) Stock returns and volatility on China's stock markets, Journal of Financial Research, 24(4), 523-543.

Saka, O., Fuertes, A. M., and Kalotychou, E. (2015) ECB policy and Eurozone fragility: Was De Grauwe right?, Journal of International Money and Finance, 54, 168-185. 


\section{Appendix A}

Figure 1. CPI plot for Gambia.

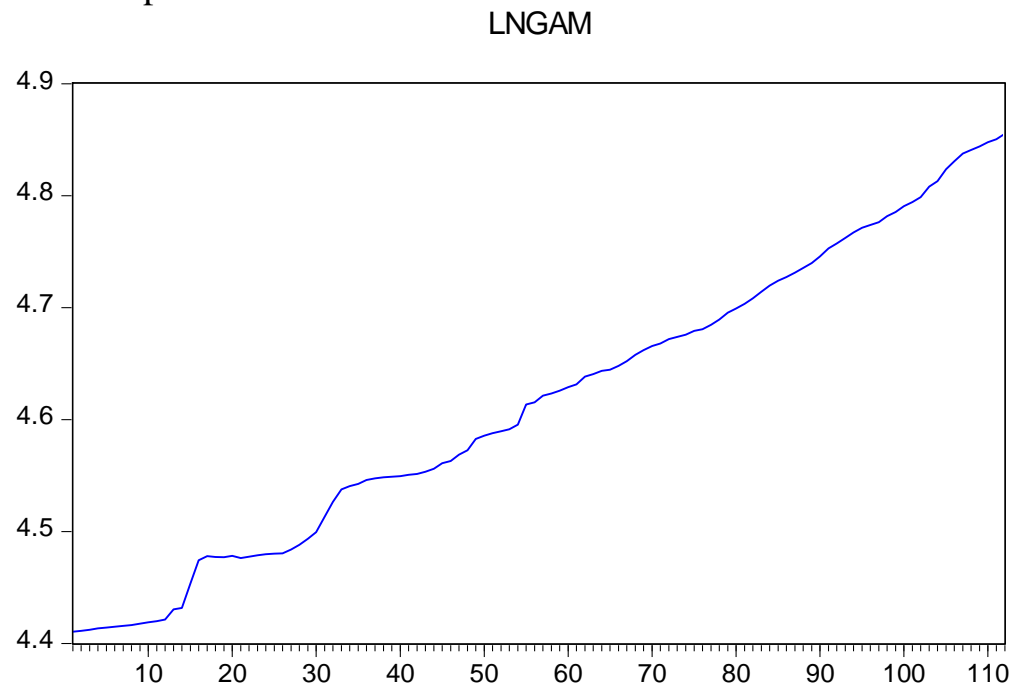

Figure 2. CPI plot for Ghana.

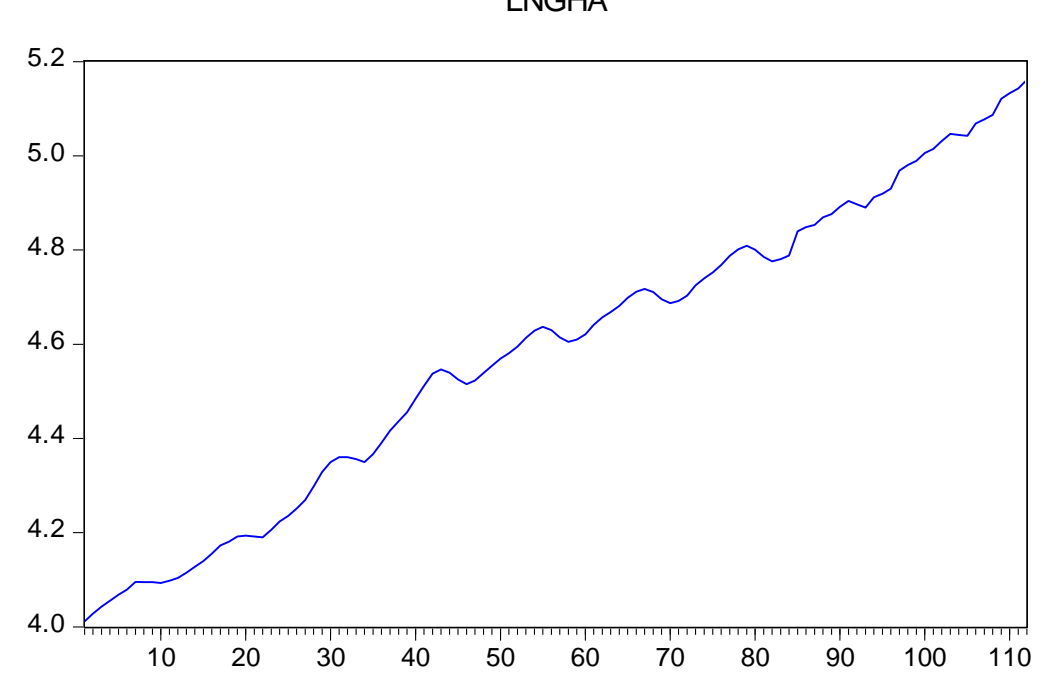

Figure 3. CPI plot for Guinea.

LNGUI

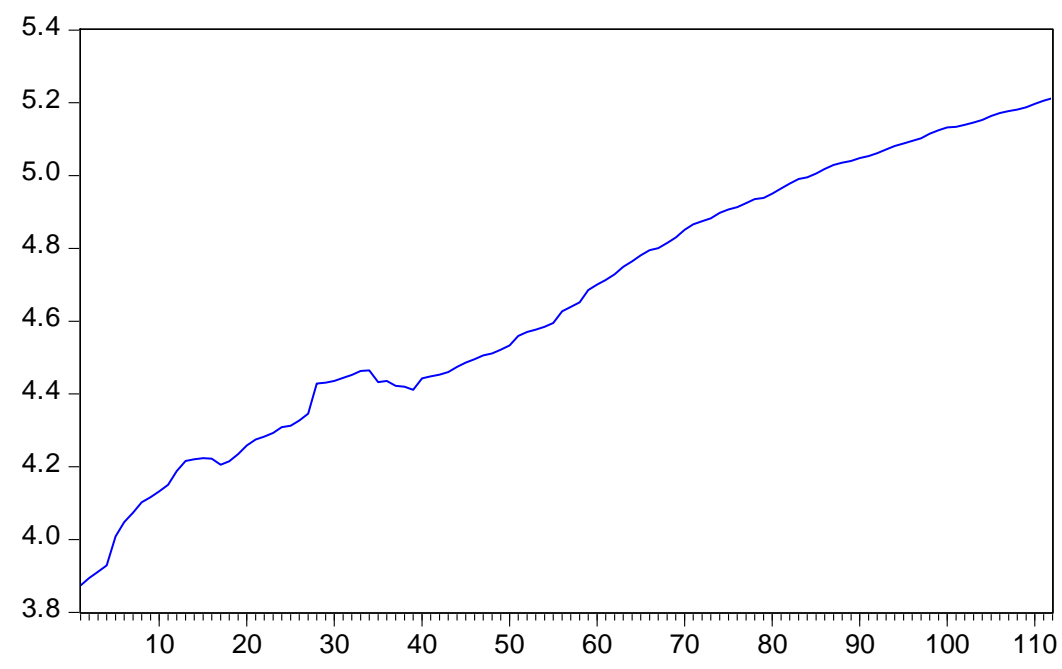


Figure 4. CPI plot for Liberia.

\section{LNLIB}

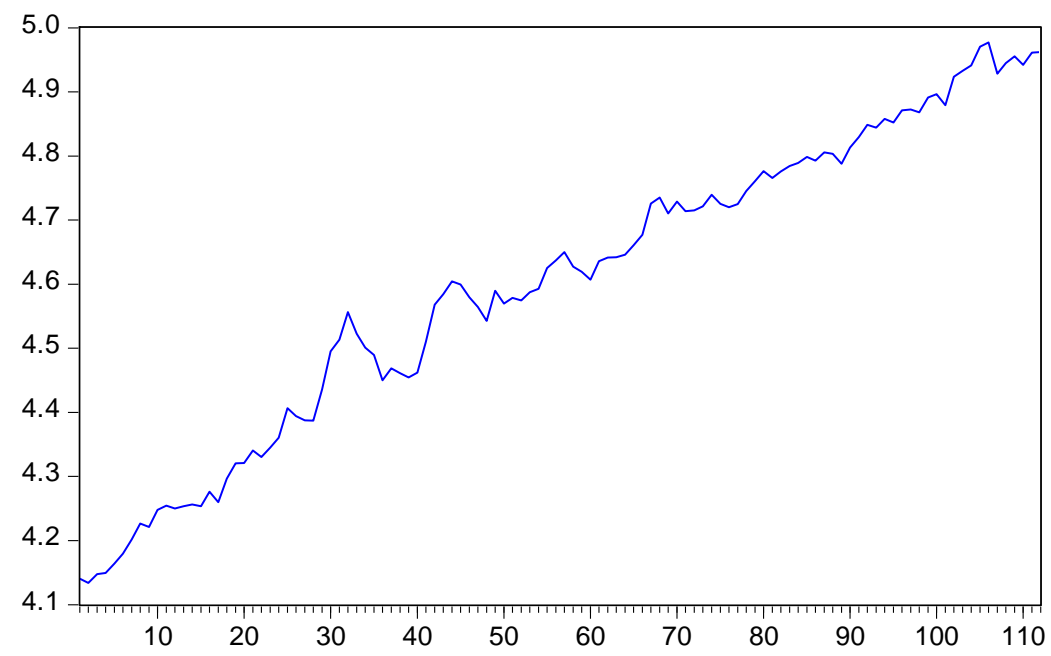

Figure 5. CPI plot for Nigeria.

LNNIG

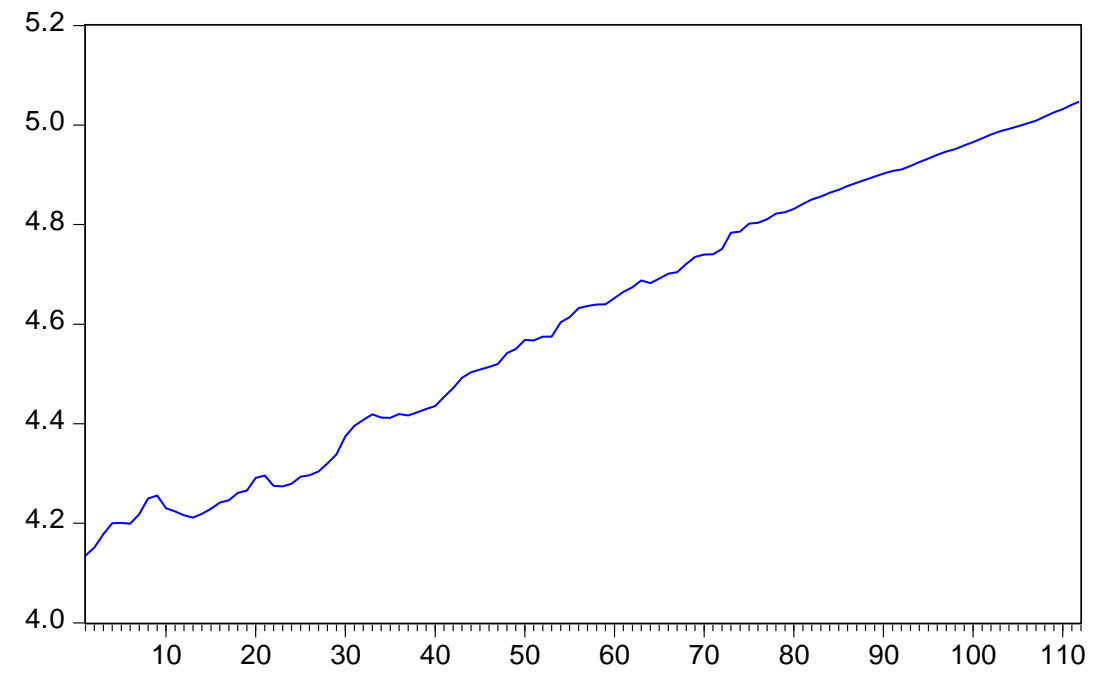

Figure 6. CPI plot for Sierra Leone.

LNSIE

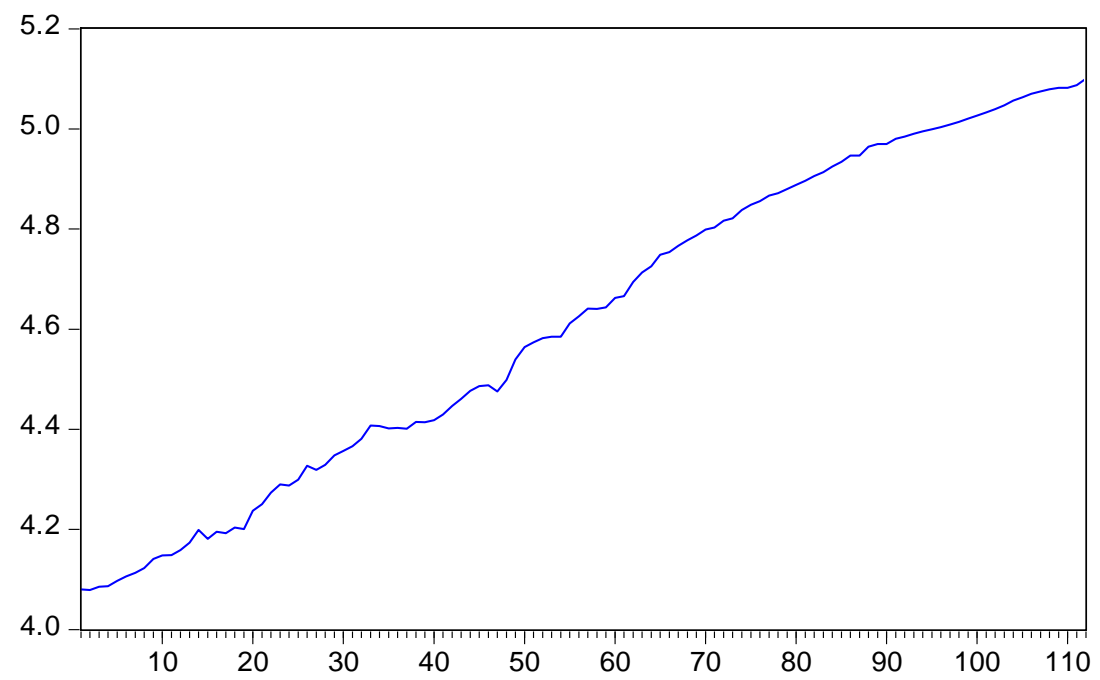

